\title{
12. A MAGNETIC STUDY OF THE BASALTS FROM HOLE 843B, HAWAIIAN ARCH ${ }^{1}$
}

\author{
H. Paul Johnson ${ }^{2}$ and Janet E. Pariso ${ }^{2}$
}

\begin{abstract}
We present rock magnetic data on 10 samples recovered from ODP Hole 843B. The 95-m.y.-old basalts have moderately high magnetization values, and Curie temperature measurements show that these basalts have undergone systematic low-temperature oxidation. High values for bulk coercivity indicate that the remanent magnetization is likely to be stable over geological time, and low viscous remanent magnetization coefficients measured for these samples argue that acquisition of viscous remanent magnetization is not likely to be geologically important in these samples. Unfortunately, formation of the Hole 843B crustal section at the beginning of the Cretaceous Normal Magnetic Superchron does not allow any simple test of the hypothesis that a substantial component of chemical remanent magnetization, in the direction of the field present during oxidation, is added soon after formation (Raymond and LaBrecque, 1987).
\end{abstract}

\section{INTRODUCTION}

Hole 843B was drilled on the Hawaiian Arch, southwest of the island of Oahu, to prepare a site for the Ocean Seismographic Network (see Dziewonski, Wilkens, Firth, et al., 1992). Drilling at Site 843 penetrated $243 \mathrm{~m}$ of sediment and $70 \mathrm{~m}$ of basaltic crust formed approximately 95 m.y. ago during the Cretaceous Normal Magnetic Superchron. Preliminary geochemical studies indicate that the recovered basalt ranges in composition from normal to enriched mid-oceanridge basalt (MORB). In addition, the depth to basement at Site 843, $4650 \mathrm{~m}$, is somewhat shallower than predicted by current models of lithospheric cooling (e.g., Stein and Stein, 1992). Although this crustal section may have been influenced by the proximity of the Hawaiian hotspot, it still represents the potential for useful data collection in an age interval in which direct rock samples are extremely rare.

The focus of our study is the examination of the magnetic properties of old oceanic crust. In particular, we are interested in the alteration of the magnetic minerals within these basalts, and the ability of these basalts to carry a strong, stable remanent magnetization over geologically significant periods of time. An early compilation of magnetic data from Deep Sea Drilling Project (DSDP) drill holes suggested that the average magnetization of the upper, extrusive basalts varies systematically with age (Bleil and Petersen, 1983). More recently, Johnson and Pariso (1993) compiled hard rock magnetic data from both DSDP and ODP holes that penetrated crust formed in a "normal" mid-ocean-ridge environment (i.e., back-arc basin and hotspot locations were excluded). For the first 30 m.y., the intensity of natural remanent magnetization $\left(J_{0}\right)$ of extrusive basalts shows a steady decrease with age, from 12 to $2.6 \mathrm{~A} / \mathrm{m}$, a direct result of progressive low-temperature oxidation (Irving, 1970; Marshall and Cox, 1971; Johnson and Atwater, 1977). In contrast, crust older than $80 \mathrm{~m}$.y. shows a moderately high average magnetization of $5.3 \mathrm{~A} / \mathrm{m}$. Although the oxidation state of the magnetic minerals within the $30-\mathrm{m} . \mathrm{y}$. basalts is similar to that of those older than 80 m.y., the total amount of magnetic material is substantially less (based on values of saturation magnetization). Therefore, the high intensity of magnetization of the older rock samples has been attributed to an increase in the abundance in the magnetic FeTi-oxide minerals (Johnson and Pariso, 1993). Unfortunately, the small number of drill holes in crust between the ages of 30 and $80 \mathrm{~m}$.y. did not allow the authors to determine whether the change in intensity of magnetization in crust occurs gradually with age, or abruptly at some point in time between

' Wilkens, R.H., Firth, J., Bender, J., et al., 1993. Proc. ODP, Sci. Results, 136: College Station, TX (Ocean Drilling Program),

${ }^{2}$ School of Oceanography, University of Washington, Seattle, WA 98195 , U.S.A.
30 and 80 m.y. Because the Leg 136 basalts fulfill all of the criteria of "normal" mid-ocean-ridge basalts as described by Johnson and Pariso (1993), they provide an important estimate of the intensity of magnetization of Cretaceous age oceanic basalts.

\section{MEASUREMENTS}

For our study of the magnetic properties of the drill core, 6 minicore and 4 minicube samples were selected for detailed magnetic measurements by the Shipboard Scientific Party and are listed by sample number in Table 1. In our shore-based laboratory study, we measured intensity of natural remanent magnetization $\left(J_{0}\right)$, weak-field susceptibility $(k)$, and the rock magnetic properties of saturation magnetization $\left(J_{\mathrm{s}}\right)$, Curie temperature $\left(T_{\mathrm{c}}\right)$ and the hysteresis loop parameters of $J_{\mathrm{rs}} / J_{\mathrm{s}}$ and $H_{\mathrm{re}} / H_{\mathrm{c}}$. The latter two ratios are derived from magnetic hysteresis loops, and are characteristic of the magnetic domain state and grain size (e.g., Day et al., 1977; Stacey and Banerjee, 1974). In addition, in an effort to estimate the stability of the remanent magnetization over time, we measured the short-term acquisition of viscous remanent magnetization (VRM) using a Schonstedt viscous remanence magnetometer with acquisition times of $600 \mathrm{~s}$ ( $10 \mathrm{~min})$. Samples were undemagnetized at the time of the VRM measurements, and were stored for several weeks in a nonmagnetic shield prior to measurement of the acquisition coefficient (Tivey and Johnson, 1981). The stable magnetic directions from most of the drill core samples and their tectonic significance are reported by the Leg 136 Scientific Party (Dziewonski, Wilkens, Firth, et al., 1992).

\section{Sample Averages}

Table 1 shows the individual sample magnetic measurements, which are averaged over the entire sample suite in Table 2 . The mean value of $J_{0}$ is $4.4 \mathrm{~A} / \mathrm{m}$, with a standard deviation of $1.4 \mathrm{~A} / \mathrm{m}$. Correction to the equator (for global comparison) results in an insignificant change of the average value to $4.1 \mathrm{~A} / \mathrm{m}$. Weak-field susceptibility measurements were carried out in the Schonstedt VRM magnetometer, and averaged $2.3 \times 10^{-2} \mathrm{SI}$ units. One index to the ability of oceanic crustal rocks to contribute to the source layer for marine magnetic anomalies is to compare the remanent magnetization $\left(J_{0}\right)$ of the rock to the magnetization induced in the formation by the ambient geomagnetic field. This is commonly done via the Koenigsberger, or $Q$, ratio where $Q=J_{0} \times \mu_{0} /(k \times H), \mu_{0}$ is the permeability of free space and $H$ is the intensity of the ambient field (often taken as $0.05 \mathrm{mT}$ for convenience). Applying this ratio to the present data results in an average $Q$ value of 4.8 , well above the required value of $Q=1.0$ for a marine magnetic anomaly source layer (e.g., Vacquier, 1972). Satu- 
Table 1. Magnetic properties for individual samples from Hole 843B.

\begin{tabular}{|c|c|c|c|c|c|c|c|c|}
\hline $\begin{array}{l}\text { Core, section, } \\
\text { interval }\end{array}$ & $\begin{array}{c}J_{0} \\
(\mathrm{~A} / \mathrm{m})\end{array}$ & $\begin{array}{l}\text { Susceptibility } \\
\text { (SI units) }\end{array}$ & $\begin{array}{l}\text { Alpha } \\
(\mathrm{A} / \mathrm{m} / \mathrm{s})\end{array}$ & $\begin{array}{c}\mathrm{J}_{\mathrm{s}} \\
\left(\mathrm{A} \cdot \mathrm{m}^{2} / \mathrm{kg}\right)\end{array}$ & $J_{r s} / J_{s}$ & $\begin{array}{c}H_{\mathrm{c}} \\
(\mathrm{mT})\end{array}$ & $H_{\mathrm{rc}} / H_{\mathrm{c}}$ & $\begin{array}{l}T_{\mathrm{c}} \\
\left({ }^{\circ} \mathrm{C}\right)\end{array}$ \\
\hline \multicolumn{9}{|l|}{$843 B-$} \\
\hline $1 \mathrm{R}-1,4-6 \mathrm{~cm}$ & 5.5 & $4.32 \times 10^{-2}$ & $4.7 \times 10^{-2}$ & 1.85 & 0.09 & 2.8 & 2.0 & 325 \\
\hline IR-1,94-96 cm & 6.7 & $4.42 \times 10^{-2}$ & $9.7 \times 10^{-2}$ & 2.40 & 0.11 & 3.4 & 2.0 & 277 \\
\hline IR- $2,54-56 \mathrm{~cm}$ & 4.9 & $1.66 \times 10^{-2}$ & $9.9 \times 10^{-3}$ & 0.97 & 0.18 & 9.0 & 1.4 & 315 \\
\hline $1 \mathrm{R}-4,27-29 \mathrm{~cm}$ & 4.3 & $3.29 \times 10^{-2}$ & $4.0 \times 10^{-2}$ & 1.53 & 0.13 & 4.2 & 1.8 & 329 \\
\hline $1 \mathrm{R}-6,17-19 \mathrm{~cm}$ & 4.6 & $1.55 \times 10^{-2}$ & $8.0 \times 10^{-3}$ & 0.64 & 0.28 & 11.3 & 1.3 & 315 \\
\hline $2 \mathrm{R}-2,21-23 \mathrm{~cm}$ & 1.1 & $1.27 \times 10^{-2}$ & $1.8 \times 10^{-3}$ & 0.82 & 0.35 & 12.0 & 1.4 & 337 \\
\hline $3 \mathrm{R}-2,17-19 \mathrm{~cm}$ & 4.4 & $1.57 \times 10^{-2}$ & $7.8 \times 10^{-3}$ & 0.93 & 0.37 & 14.2 & 1.4 & 330 \\
\hline $3 \mathrm{R}-2,26-28 \mathrm{~cm}$ & 4.5 & $1.48 \times 10^{-2}$ & $8.0 \times 10^{-3}$ & 0.59 & 0.41 & 13.6 & 1.3 & 323 \\
\hline $4 \mathrm{R}-2,11-13 \mathrm{~cm}$ & 4.3 & $1.75 \times 10^{-2}$ & $2.9 \times 10^{-3}$ & 0.86 & 0.26 & 8.0 & 1.5 & 321 \\
\hline $4 \mathrm{R}-2,68-70 \mathrm{~cm}$ & 3.6 & $1.81 \times 10^{-2}$ & $5.8 \times 10^{-3}$ & n.m. & n.m. & n.m. & n.m. & 331 \\
\hline
\end{tabular}

Note: $\mathrm{n} \cdot \mathrm{m} .=$ not measured.

Table 2. Mean values and standard deviation of magnetic properties measured on samples from Hole 843B.

\begin{tabular}{lccc}
\hline & Mean & $\begin{array}{c}\text { Standard } \\
\text { Deviation }\end{array}$ & $\begin{array}{c}\text { Number of } \\
\text { Samples }\end{array}$ \\
\hline$J_{0}(\mathrm{~A} / \mathrm{m})$ & 4.4 & 1.4 & 10 \\
$k(\mathrm{SI}$ units $)$ & $2.3 \times 10^{-2}$ & $1.2 \times 10^{-2}$ & 10 \\
Alpha $(\mathrm{A} / \mathrm{m} / \mathrm{s})$ & $2.3 \times 10^{-2}$ & $3.0 \times 10^{-2}$ & 10 \\
$J_{\mathrm{s}}$ & 1.18 & 0.62 & 9 \\
$J_{\mathrm{rs}} / J_{\mathrm{s}}$ & 0.24 & 0.12 & 9 \\
$H_{\mathrm{c}}(\mathrm{mT})$ & 8.7 & 4.4 & 9 \\
$H_{\mathrm{rc}} / H_{\mathrm{c}}$ & 1.58 & 0.29 & 9 \\
$T_{\mathrm{c}}\left({ }^{\circ} \mathrm{C}\right)$ & 320 & 17 & 10 \\
\hline
\end{tabular}

ration magnetization $\left(J_{5}\right)$, an indicator of magnetic mineralogy composition and abundance, has an average value of $1.17 \mathrm{~A} \cdot \mathrm{m}^{2} / \mathrm{kg}$. Curie temperature $\left(T_{\mathrm{c}}\right)$, a measurement of oxidation state, has an average value of $320^{\circ} \mathrm{C}$, and this value is within the expected range for samples with a crustal age of $95 \mathrm{~m}$.y. (Johnson and Pariso, 1993). The hysteresis loop parameters of $J_{\mathrm{rs}} J_{\mathrm{s}}$ and $H_{\mathrm{c}} / H_{\mathrm{rc}}$ indicate that the grain size of the magnetic minerals (presumed titanomaghemite, from the irreversible $T_{\mathrm{c}}$ behavior) is similar to that observed in other mid-ocean-ridge basalts and can best be described as pseudo-single domain.

\section{Viscous Remanent Magnetization}

The relevance of laboratory-measured VRM acquisition coefficients, which are typically made on samples over time intervals of minutes or hours, to crustal rocks that have been exposed to changing magnetic fields on the scale of millions of years, is an unresolved question. Previous work (Lowrie and Kent, 1978) has shown that the slope of the acquisition curve (traditionally plotted as new VRM remanence acquired vs. $\log$ [time]) is not constant, and can decrease substantially when relatively long (i.e., months) laboratory times are used. Simple logistical considerations, largely magnetometer sensor stability, limited acquisition times during our experiments to $10 \mathrm{~min}$ per sample. The importance of the secondary magnetization associated with these 95 -m.y.-old rocks requires that we carefully consider the resulting data. However, any geological interpretation of the results should be tempered with the continued reminder that the acquisition times were limited to $600 \mathrm{~s}$ and the acquisition coefficient may not be constant over an additional 10 or 11 orders of magnitude ( $\left.1 \mathrm{~m} . \mathrm{y}_{\mathrm{s}}=3 \times 10^{13} \mathrm{~s}\right)$. With that caveat, however, we still believe that the short-term VRM coefficients represent a useful measure of the upper limit of the stability of the remanent magnetization.

Coefficients of VRM acquisition (Alpha) are displayed in Table 1 and were determined for individual samples using the relationship

$$
J(\mathrm{t})-J(\mathrm{i})=(\text { Alpha }) \times \log (\mathrm{T}),
$$

where $J(\mathrm{i})$ is the initial magnetization, and $J(\mathrm{t})$ is the magnetization measured after time $\mathrm{T}$ in an applied field. For perspective, it can be shown that a continuous acquisition coefficient of $0.023 \mathrm{~A} / \mathrm{m} / \mathrm{s}$ (the mean value of Alpha for these samples) would result in a magnetization of $0.3 \mathrm{~A} / \mathrm{m}$ over a period of $1 \mathrm{~m} . \mathrm{y}$. In comparison with the mean $J_{0}$ value for these samples $(4.4 \mathrm{~A} / \mathrm{m})$, this hypothetical component of viscous magnetization is only $7 \%$ of the total observed magnetization. Clearly, based on these measurements, VRM acquisition cannot be considered an important source of secondary magnetization in the Leg 136 crustal rocks.

\section{DISCUSSION}

Our study of magnetic properties of the Leg 136 samples shows that the magnetic behavior of these basalts is very similar to mid-oceanridge basalts that have undergone only a moderate degree of low-temperature oxidation. Specifically, the average $J_{0}$ value of $4.4 \mathrm{~A} / \mathrm{m}(4.1$ $\mathrm{A} / \mathrm{m}$ if corrected to equatorial values), and an average $Q$ value near 5 , are very typical of the values found for older oceanic crust (see Fig. 1). In addition, the thermomagnetic curves for the Leg 136 basalts were observed to be strongly irreversible with $T_{\mathrm{c}}$ values averaging $320^{\circ} \mathrm{C}$. If we assume that the ulvospinel content of the primary titanomagnetite was approximately $62 \%$ in the Hole 843 basalts, these Curie temperatures are characteristic of titanomaghemite formed during low-temperature oxidation of titanomagnetite in submarine basalts (Marshall and Cox, 1971; Johnson and Atwater, 1977). These data argue that the Hole $843 \mathrm{~B}$ core samples are typical mid-ocean-ridge extrusive rocks (pillow basalts), which have undergone low-temperature oxidation due to the exposure to cold seawater relatively soon after crustal formation. If this is indeed the case, the primary magnetization of the rocks is an initial thermal remanent magnetization (TRM), which has been sub-

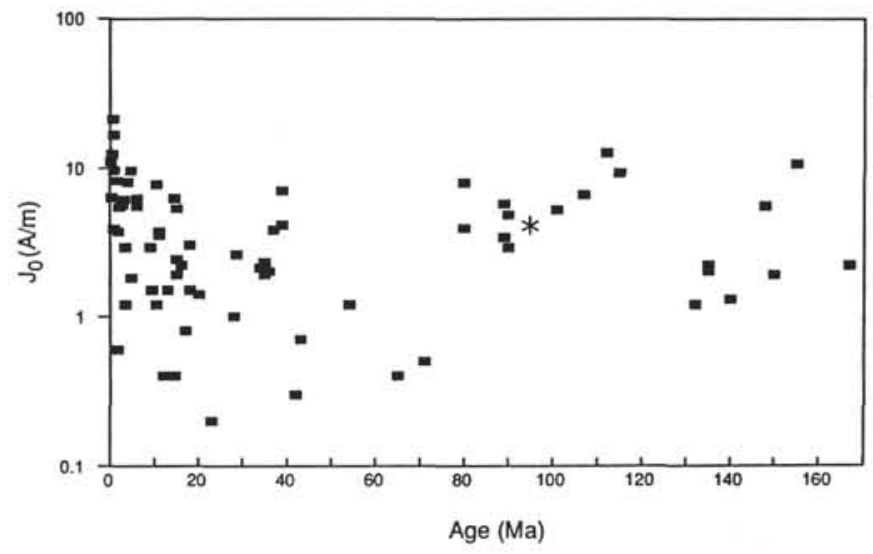

Figure 1. Mean values of magnetization calculated for individual DSDP/ODP drill sites and corrected to equatorial values are plotted vs. age (after Johnson and Pariso, 1993). The mean $J_{0}$ value for Leg 136 samples is shown with an asterisk. 
sequently modified to a chemical remanent magnetization (CRM) by the oxidation process (Johnson and Merrill, 1973). Because the geomagnetic field was constant polarity for $11 \mathrm{~m} . \mathrm{y}$. after the formation of the crust at Hole 843B, any secondary component of magnetization acquired during oxidation would be in the same direction as the primary TRM. As a result, there is no easy test to determine if the rocks have acquired a post-formation CRM that is independent of the original TRM component (e.g., Raymond and LaBrecque, 1987). For the same reason, it is difficult to test whether these basalts acquired a VRM that was subsequently "hardened" by low-temperature oxidation (Beske-Diehl, 1989; 1990).

A second possible source of post-formation magnetization is the addition of a VRM component. Our short-term VRM acquisition tests show that there appears to be a positive correlation between high NRM intensity and high acquisition coefficients (Fig. 2). At face value, this proposed positive correlation suggests that the high NRM values may, at least partially, be due to the addition of a post-formation magnetization. Several lines of evidence point away from this being the case, however. First, the data set in Figure 2 is small and scattered, and the proposed correlation is relatively weak. Finally, Figure 3 shows the relationship between VRM coefficient and $J_{\mathrm{rs}} / J_{\mathrm{s}}$, indicating that only the samples with a larger effective magnetic grain size (i.e., those with low $J_{\mathrm{rs}} / J_{\mathrm{s}}$ values) show substantial VRM acquisition. Because the bulk of the volume of extrusive pillow basalts is contained in the outer (fine-grained) rim of the pillows (Marshall and Cox, 1971), the presumed coarse-grained pillow interiors, which show the relatively high VRM acquisition, are not likely to be volumetrically important.

\section{CONCLUSIONS}

New magnetic data from the shallow drill hole, Hole 843B, show that 95 -m.y.-old basalts have moderately high magnetization values and have only undergone systematic low-temperature oxidation. High values for bulk coercivity (Table 1) also indicate that the magnetization is likely to be stable over geological time. Unfortunately, formation of the Hole 843B crustal section at the beginning of the Cretaceous Normal Magnetic Superchron does not allow any simple test of the hypothesis that a substantial component of CRM, in the direction of the field present during oxidation, is added soon after formation (Raymond and LaBrecque, 1987). The presence of thermally unstable titanomaghemite in the Hole 843B samples (determined from the $T_{\mathrm{c}}$ measurements) does allow us to rule out large-scale thermal reheating as the source of the high crustal magnetization observed during the Cretaceous. Finally, the low VRM coefficients measured for these samples argue that acquisition of viscous remanent magnetization is not likely to be geologically important in these samples.

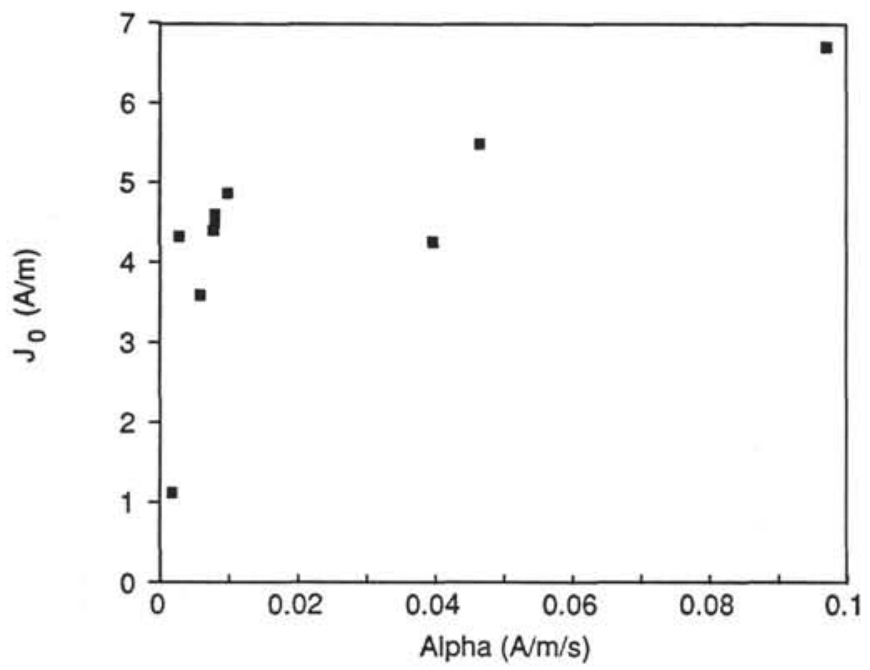

Figure 2. Intensity of natural remanent magnetization $\left(J_{0}\right)$ is plotted vs. the VRM acquisition coefficient (Alpha).

\section{REFERENCES}

Beske-Diehl, S.J., 1989. Comment on "Magnetization of the oceanic crust: thermoremanent magnetization or chemical remanent magnetization?" by C.A. Raymond and J.L. LaBrecque. J. Geophys. Res., 94:3046-3048.

, 1990. Magnetization during low-temperature oxidation of seafloor basalts: no large-scale chemical remagnetization. J. Geophysics. Res., 95:413-421.

Bleil, U., and Petersen, N., 1983. Variations in magnetization intensity and low-temperature titanomagnetite oxidation of ocean floor basalts. Nature, 301:384-388.

Day, R., Fuller, M., and Schmidt, V.A., 1977. Hysteresis properties of titanomagnetites: grain-size and compositional dependence. Phys. Earth Planet. Inter., 13:260-267.

Dziewonski, A., Wilkens, R., Firth, J., et al., 1992. Proc. ODP, Init. Repts., 136: College Station, TX (Ocean Drilling Program).

Irving, E., 1970 . The Mid-Atlantic Ridge at $45^{\circ} \mathrm{N}$. XIV. Oxidation and magnetic properties of basalt; review and discussion. Can. J. Earth Sci., 7:1528-1538.

Johnson, H.P., and Atwater, T., 1977. Magnetic study of basalts from the Mid-Atlantic Ridge, lat. $37^{\circ}$ N. Geol. Soc. Am. Bull., 88:637-647.

Johnson, H.P., and Merrill, R.T., 1973. Low-temperature oxidation of titanomagnetite and the implications for paleomagnetism. J. Geophys. Res., 78:4938-4949.

Johnson, H.P., and Pariso, J.E., 1993. Variations in oceanic crustal magnetization: systematic changes in the last 160 million years. J. Geophys. Res., 98:435-445.

Lowrie, W., and Kent, D.V., 1978. Characteristics of VRM in ocean basalts. J. Geophys., 44:297-315.

Marshall, M., and Cox, A., 1971. Effect of oxidation on the natural remanent magnetization of titanomagnetite in suboceanic basalt. Nature, 40:28-31.

Raymond, C.A., and LaBrecque, J.L., 1987. Magnetization of the oceanic crust: Thermoremanent magnetization or chemical remanent magnetization? J. Geophys. Res., 92:8077-8088.

Stacey, F., and Banerjee, S.K., 1974. The Physical Principles of Rock Magnetism: Amsterdam (Elsevier).

Stein, C.A., and Stein, S., 1992. A model for the global variation in oceanic depth and heat flow with lithospheric age. Nature, 359:123-129.

Tivey, M., and Johnson, H.P., 1981. Characterization of viscous remanent magnetization in single- and multi-domain magnetite grains. Geophys. Res. Lett., 8:217-220.

Vacquier, V., 1972. Geomagnetism in Marine Geology: Amsterdam(Elsevier).

Abbreviations for names of organizations and publication titles in ODP reference lists follow the style given in Chemical Abstracts Service Source Index (published by American Chemical Society).

Date of initial receipt: 3 September 1992

Date of acceptance: 5 May 1993

Ms 136SR-215

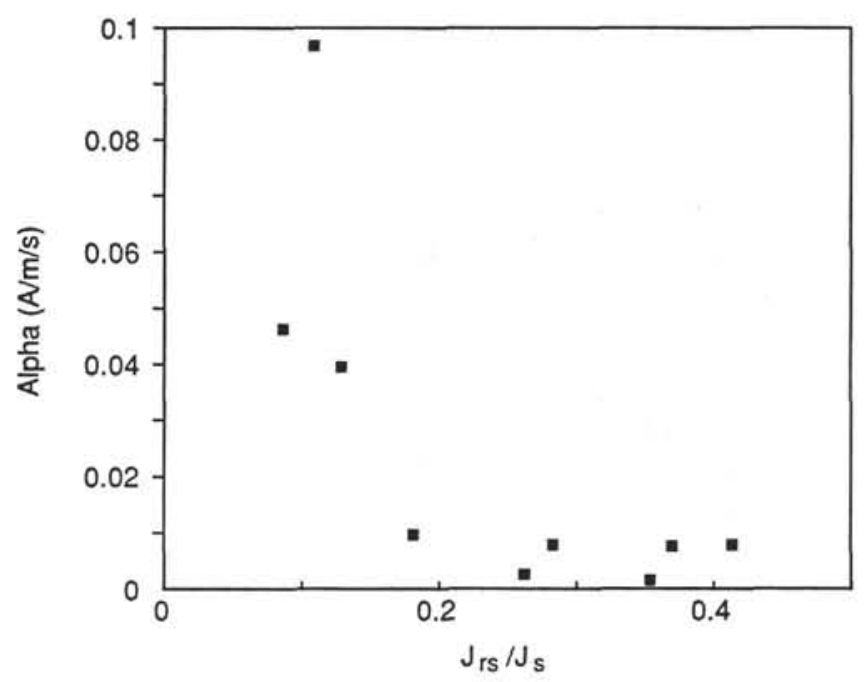

Figure 3. The VRM acquisition coefficient (Alpha) is plotted vs. $J_{r s} / J_{s}$ and shows that grains with larger effective magnetic grain size have high Alpha values. 